\title{
Parent-Child Interactions With Anxious Children and With Their Siblings: An Observational Study
}

\author{
Paula M. Barrett \\ The University of Queensland, Australia and Pothways Health and Research Centre, Brisbone, Australia \\ Tara Fox \\ Griffith University, Austrolia \\ Lara J. Farrell \\ The University of Queensland, Australia and Pathways Health and Research Centre, Brisbane, Australia
}

In the present study, parent-child interactions with anxious children were compared to parent-child interactions with the anxious children's nonsymptomatic siblings and parent-child interactions with nonclinic children. Participants included 33 anxious children, their parents and siblings, and 14 nonclinic children and their parents. Parent-child interactions were observed during two discussion tasks related to anxiety-provoking or challenging situations. Parent-child interactions were coded for the following variables: control, warmth, reward of coping behaviour and task involvement. Consistent with previous research, parents in the anxious group showed more control, less paternal warmth and less maternal reward of coping behaviour toward their anxious child compared to parents of nonclinic children. Parent-child interactions with the anxious child were similar to parent-child interactions with the nonsymptomatic sibling, with the exception of fathers who exhibited more control toward their anxious child. Parent-sibling interactions, however, also resembled the nonclinic parent-child interactions, with mothers of anxious children showing more control toward their nonsymptomatic child than mothers of nonclinic children. These findings suggest that the relationships of each parent and their anxious child may be influenced by how the parent and child interact with each other. Suggestions for future research are discussed.

$\mathrm{P}$ arenting behaviours and the nature of the parent-child relationship are often implicated in the aetiology and maintenance of childhood anxiety disorders (e.g., Barrett, Rapee, Dadds, \& Ryan, 1996; Chorpita, Brown, \& Barlow, 1998; Cobham, 1998; Dadds \& Barrett, 1996; Ginsburg, Silverman, \& Kurtines, 1995; Manassis, 2001; Rapee, 1997; Siqueland, Kendall, \& Steinberg, 1996). Support for this comes from a range of studies in which a variety of methodologies were used, including both clinical and nonclinical samples, child and retrospective adult report, questionnaire and observational data. Further, both specific measures of parenting and assessment of the family environment as a whole have been used in studies. Taken together, the

Address for correspondence: Dr Paula Barrett, School of Psychology, The University of Queensland. Postal address PO Box 5699, West End QLD 4101, Australia. E-mailinfo@pathwayshrc.com.au

Behaviour Change I Volume 22 I Number $4 \mid 2005$ i pp. 220-235 
results of these studies have indicated that the nature of the parent-child relationship is different for anxious children compared to nonclinic children, and that it is the dimensions of parental control and rejection (versus warmth) that consistently appear to be most strongly related to childhood anxiety.

It has been found in studies of parenting behaviour in which clinical samples were used that compared to nonclinic controls, parents of anxious children are more controlling, more aversive (Dumas \& LaFreniere, 1993; Dumas, LaFreniere, \& Serketich, 1995; Last \& Strauss, 1990) and more restrictive (Krohne \& Hock, 1993). Parents of anxious children are also less accepting and less granting of psychological autonomy compared to nonclinic parents (Siqueland et al., 1996). Similarly, in studies of nonclinic children, child ratings of parental control, anxious rearing and rejection have been positively correlated with symptoms of anxiety (Grüner, Muris, \& Merckelbach, 1999; Muris \& Merckelbach, 1998).

Likewise, researchers examining the family environment generally suggest that compared to nonanxious children, children with anxiety disorders are more likely to describe their family environment as less promoting of independence (Messer $\&$ Beidel, 1994), less sociable, less supportive, and more conflictual and enmeshed (Stark, Humphrey, Crook, \& Lewis, 1990). Such family environments, characterised by less cohesion and promotion of independence and higher levels of control and conflict, have additionally been found to be the type of family environment that children at risk of developing an anxiety disorder have (Silverman, Cerny, Nelles, \& Burke, 1988). More recently, Chorpita et al. (1998) found that a family environment that was characterised by few opportunities for a child to experience personal control was linked with negative affect and anxiety.

Clearly there is increasing research evidence supporting the link between the family environment, parent-child relationships and childhood anxiety disorders. Implicated in this research is that a parent-child relationship that is characterised by control, rejection, lack of support of autonomy and conflict is associated with anxiety in the child. How this relationship style develops, however, is still not clear. It is possible that a high level of parental control interacts with a child's predisposition for anxious behaviour, resulting in the development of anxiety in the vulnerable child. In turn, the child's tendency for avoidance, shyness or worry may further enhance overprotection or controlling behaviour in a parent.

Thus, the question remains regarding the extent to which the characteristics of the parent-child relationship are a function of the child's characteristics and the extent to which they can be attributed to the parent's child-rearing style. In their discussion of the roles that family environment and parenting behaviour play in childhood anxiety, Siqueland et al. (1996) highlight that increased knowledge of parent-sibling interactions may provide further information about the interaction patterns that are related to anxiety. They state that:

Researchers may be able to more carefully delineate the direction of causality by examining the interaction between the parents of children with anxiety disorders and the nonsymptomatic siblings of those children to see if they interact differently with their children with anxiety disorders than with their other children (p. 234).

On average, siblings share about $50 \%$ of their genetic make-up and are usually raised in the same family and community environments. Given the random nature of genetic transmission, however, the correlations between siblings on dimensions such as personality are low (see Daniels, 1986). In addition, when using twin and adoption studies researchers have indicated that the whole of this small sibling correlation can 
be accounted for by genetic similarity (Rowe \& Plomin, 1981). The extent to which siblings' environmental factors are seen as similar is therefore negligible (Dunn \& Plomin, 1991; Rowe \& Plomin, 1981). Increasingly, researchers have concluded that environmental influences make siblings raised in the same family as different as randomly selected pairs of unrelated children since it is nonshared environments that appear to be important (Plomin \& Daniels, 1987).

Thus, while it appears that genetic factors make siblings similar, it is nonshared environmental factors that make children in the same family different (Dunn, Stocker, \& Plomin, 1990). It has been shown in previous research that children raised in the same family have notably different relationships with their parents, and that sibling relationships are perceived differently by each child (Dunn $\&$ Plomin, 1991). Hoffman (1991) argued that sibling dissimilarity is not surprising given that one's experience of 'family' is a result of the interaction between the individual and environment. Individual variables such as age differences, birth order, gender, genetic make-up and idiosyncratic experiences all contribute to the variance in siblings' objective and subjective experiences of their family.

Given the role of individual child characteristics in determining the nature of a child's relationship with their parent, it may be hypothesised that the relationship between a parent and an anxious child will be different to the relationship between that same parent and a nonanxious child. However, some theoretical models suggest that the nature of parent-child relationships is influenced by both child and parent characteristics (e.g., Minuchin, 1974). Therefore, while differences in the temperament, attachment or learning experiences of siblings may work to make parent-child relationships in the same family different, these same characteristics in the parent, common to their relationship with all children, would work to make them similar. Support for similarities in the relationships within the same family has been shown in studies examining the influence of genetics on the nature of family relationships (O'Connor, Hetherington, Reiss, \& Plomin, 1995; Rende, Slomkowski, Stocker, Fulker, \& Plomin, 1992). Thus, while it is anticipated that parent-child relationships involving anxious children may differ from those involving their nonanxious siblings due to child characteristics or differential parenting, by the same token, it is likely that these parent-sibling relationships may also differ from relationships between nonclinic children and their parents who are not related to the family. Therefore, in summary, to the extent that the characteristics of an anxious child contribute to the nature of the parent-child relationship, differences should exist between parent--sibling relationships. Alternately, to the extent that parent characteristics contribute, differences should exist between the parenting of siblings of anxious children and the parenting of nonclinic children.

To date, it has only been examined in one study whether the style of parenting found for anxious children is specific to the anxious child or if parents exhibit similar behaviours with other nonsymptomatic children in the family. In this recent study, Hudson and Rapee (2002) observed the interaction of parents with their anxious children and nonanxious siblings during the completion of a complex puzzle task. The findings were consistent with previous research in that mothers of anxious children tended to be significantly more involved and intrusive during the task than mothers of nonclinical children (Hudson \& Rapee, 2002). In addition, the authors reported that parents of anxious children behaved in the same intrusive and overinvolved manner with their nonanxious children, suggesting that parental interaction 
styles found in families with an anxious child do not occur exclusively within the relationship between the parent and anxious child. Such preliminary findings highlighted the importance of further examination of siblings of anxious children and their experiences within these parental interaction patterns.

The aim of the current study was to examine parent-child interactions with anxious children, their nonsymptomatic siblings and nonclinic children (controls) using observed discussion tasks of hypothetical situations. Direct observation has been used in a wide range of empirical studies as a more objective alternative to selfreport for assessing parent-child relationships (Barrett et al., 1996; Chorpita, Albano, \& Barlow, 1996; Cobham, Dadds, \& Spence, 1999; Shortt, Barrett, Dadds, $\&$ Fox, 2001). The findings of the present research are presented in three related sections, each testing one specific hypothesis related to parent-child interaction.

The aim of Section 1 was to replicate previous findings that indicate there are differences in parent-child relationships involving anxious children and those involving nonclinic children. Consistent with the research reviewed above, parent-child relationships with anxious children were expected to be characterised by more control, conflict and less warmth than those with nonclinic children (Hypothesis 1). The aim of Section 2 of the study was to examine whether parent-child relationships were different when they involved anxious children to when they involved the anxious children's nonanxious siblings. It was predicted that parents would behave with their nonsymptomatic child similarly to how they behaved with their anxious child (Hypothesis 2). Finally, in Section 3 parent-child relationships with siblings of anxious children were compared with parent-child relationships with nonclinic children. It was hypothesised that parents of anxious children would be more controlling toward their nonanxious children than nonclinic control parents would be toward their nonclinic control children (Hypothesis 3).

\section{Method}

\section{Participants}

Forty-seven children (aged 7 to 13 years) and their families participated in the study, comprising 33 anxious children and 14 nonclinic control children. The mean age of children in the anxious group was 10.18 years $(S D=1.72)$. All families except for one in the anxious group were of Caucasian origin, and $93.9 \%$ of parents were married. Children were included in the anxious group if they currently met diagnostic criteria for an anxiety disorder, as set out in the fourth edition of the Diagnostic and Statistical Manual of Mental Disorders (DSM-IV; American Psychiatric Association, 1994), with a clinical level of severity. The primary diagnoses for the sample included generalised anxiety disorder $(\mathrm{GAD} ; 60.6 \%)$, separation anxiety disorder (SAD; 24.2\%), social phobia (SOP; 9.1\%) and specific phobia (SpP; 6.1\%). Co-morbid diagnoses were given in 20 cases $(60.6 \%)$. Secondary anxiety diagnoses were given in 16 cases $(48.5 \%)$ : GAD $(n=2), \operatorname{SOP}(n=5), \operatorname{SpP}(n=5), \operatorname{SAD}(n=$ $3)$, and panic disorder $(n=1)$. Subclinical diagnoses of externalising disorders, oppositional defiant disorder (ODD) or attention-deficit/hyperactivity disorder (ADHD), were given to 9 children. These children remained in the study as the ODD and ADHD symptoms were subclinical and as these children were matched on all other variables, including severity of anxiety.

Siblings from families of anxious children also participated in the study, with the sibling closest in age to the anxious child being the one included in the study. In the 
33 families, 4 siblings met criteria for a clinical-level anxiety disorder and were excluded from the analyses. Thus, Section 2 was based on the 29 remaining children and their siblings. To be eligible for inclusion in the study, siblings needed to be aged between 6 and 16 years and be within 4 years of the age of the target child. The mean absolute age difference between siblings was 2.24 years $(S D=0.91)$. The mean age of the children in the anxious group was 10.28 years $(S D=1.73)$ and the mean age of their siblings was 10.72 years $(S D=2.81)$. Eight $(27.6 \%)$ of the sibling pairs were same sex females, $9(31 \%)$ were same sex males and $12(41.4 \%)$ were mixed gender pairs. In $48.3 \%$ of cases $(n=14)$, the anxious child was the older sibling.

The mean age of the nonclinic children was 9.86 years $(S D=1.75)$. One nonclinic family self-identified as being Asian, with the remainder of the nonclinic sample being Caucasian. A total of $71.4 \%$ of parents in the nonclinic group were married. To be eligible for inclusion in the nonclinic group, children needed to not meet the criteria for a DSM-IV diagnosis.

\section{Materials}

\section{Diagnostic Assessment}

Diagnostic Interview Schedule for Children, Adolescents and Parents. The Diagnostic Interview Schedule for Children, Adolescents and Parents (DISCAP; Holland \& Dadds, 1995) is a semistructured interview designed to assess anxiety, mood and disruptive disorders applicable to children and adolescents. Based on the DSM-IV (American Psychiatric Association, 1994) diagnostic criteria, the DISCAP can be used to interview parents, adolescents and children. A rating between 1 (low severity and/or interference) and 6 (high severity and/or interference) is given to indicate the severity of a disorder, with ratings of 3 or above indicating disorders in the clinical range. Reliability and validity of the DISCAP have been shown to be sound (Johnson, Barrett, Dadds, Fox, \& Shortt, 1999). Among a clinical sample of anxious children, the overall kappa agreement for parent interviews was found to be .95 for the presence of any anxiety disorder and ranged between .65 and .79 for specific anxiety diagnoses (Johnson et al., 1999). In the current study, a random sample of $57 \%$ of videotaped diagnostic interviews was watched by an independent trained clinician to determine interrater reliability. Overall kappa agreement for primary diagnoses was .92 for any anxiety disorder, .94 for GAD and .94 for SAD.

\section{Self-Report Measures}

Revised Children's Manifest Anxiety Scale. The Revised Children's Manifest Anxiety Scale (RCMAS; Reynolds \& Richmond, 1978) is a well-known self-report inventory designed to measure anxiety in children. The scale includes a total of 37 true-false items with 9 of these forming a lie scale. Example items from the scale include 'I worry a lot of the time' and 'I am nervous'. Across a wide range of age groups the RCMAS has been shown to have high internal consistency and moder-

224 ate test-retest reliability $(r=.68$ over 9 months). Good validity has also been demonstrated, with the RCMAS correlating strongly with a measure of trait anxiety $(r=.85)$ but weakly with a measure of state anxiety $(r=.35$; Reynolds \& Richmond, 1985). In addition, the RCMAS is able to discriminate anxiety-disordered children from normal controls (Perrin \& Last, 1992).

Child Behavior Checklist - Revised. The Child Behavior Checklist - Revised (CBCL-R; Achenbach, 1991) is a 118-item scale that can be used by parents of 
children and adolescents aged 4 to 18 years. The scale provides a total score and two global dimensions of behavioural problems (internalising and externalising), as well as several subscale scores. Only the global internalising and externalising behaviour-problem scales were used in this study. The internalising score is derived using the Withdrawn, Somatic Complaints, and Anxious/Depressed subscales and the externalising score uses the Aggressive Behavior and Delinquent Behavior scales. Problems are considered to be in the clinical range if scores exceed the 98 th percentile. The CBCL-R has sound psychometric properties, with high test-retest reliability for both item $(>.90)$ and scale scores (median $=.89$ ); adequate interparent agreement (median $=.66$ ); and sound content, construct and criterion validity (Achenbach, 1991; Achenbach \& Edelbrock, 1983).

Depression Anxiety Stress Scales. The Depression Anxiety Stress Scales (DASS; S. Lovibond \& Lovibond, 1993) are three scales comprising 21 items in total that assess level of depression, anxiety and tension/stress. Widely used, these well-developed scales have been shown to be reliable and valid (Brown, Chorpita, Korotitsch, \& Barlow, 1997; Clara, Cox, \& Enns, 2001; P. Lovibond \& Lovibond, 1995). Among a clinical sample, the DASS has been shown to have favourable test-retest reliability $(r=.71-81)$ and internal consistency for both a mixed diagnostic group $(\alpha>.89)$ and individual diagnostic categories $(\alpha>.88$; Brown et al., 1997).

\section{Assessment of Family Discussion Task}

Topic nomination form. In order to identify an anxiety-provoking situation relevant for families to discuss, parents completed a topic nomination form (Fox, Barrett, \& Shortt, 2002) that described six various situations commonly experienced by children. The frequency of nominations was attending a sleep over $(21.3 \%)$, giving a class presentation $(21.3 \%)$, joining a sports team $(21.3 \%)$, having a class test $(14.9 \%)$, attending or changing schools $(10.6 \%)$, or sleeping with the light off $(4.3 \%)$. In three cases $(6.4 \%)$, parents indicated that none of the suggested topics were relevant and selected a more applicable scenario. Using a Mann-Whitney $U$ test, no significant difference was found for discussion topic preference between anxious and nonclinic groups.

Discussion task. Parents completed two 5-minute discussion tasks with each of their children who were involved in the study (i.e., anxious child, sibling or nonclinic child). The first topic for each parent-child or parent-sibling discussion was the following description of an ambiguous situation: 'You see a group of students from another class playing a great game. You walk over and want to join in and you hear them laughing. What do you think is most likely to happen next? What will you do?' The second topic for discussion was nominated by the parents from the topic nomination form as a situation that was likely to elicit some anxiety for the child. Participants were instructed to discuss the child's feelings and behaviours in the situations and decide on a final solution for what the child would do in that scenario.

Coding system. Each parent-child discussion was videotaped and later coded as an indicator of the relationship between the parents and child. Using previous research as a guide in selecting appropriate variables, the coding system of Fox et al. (2002) was adapted for parent-child interactions. Variables of interest were control, warmth, task involvement and reward of coping behaviour (parents only). Shown in Table 1 are definitions and examples for each of the coded dimensions. 
TABLE 1

Parent-Child Interaction Coding Definitions

\begin{tabular}{|c|c|c|c|}
\hline & Definition & $\begin{array}{l}\text { e.g., Low level of } \\
\text { behaviour (1) }\end{array}$ & $\begin{array}{l}\text { e.g., High level of } \\
\text { behaviour (5) }\end{array}$ \\
\hline Control & $\begin{array}{l}\text { Control through } \\
\text { disregard of other's } \\
\text { opinions or dictating } \\
\text { other's actions }\end{array}$ & $\begin{array}{l}\text { Accepts or asks for } \\
\text { other's opinions, } \\
\text { Facilitates autonomous } \\
\text { thought }\end{array}$ & $\begin{array}{l}\text { Aggressively dominates } \\
\text { discussion, Instructs } \\
\text { on what to do/say }\end{array}$ \\
\hline Warmth & $\begin{array}{l}\text { Warmth, intimacy or } \\
\text { affection toward } \\
\text { (verbal/physical } \\
\text { behaviour) }\end{array}$ & $\begin{array}{l}\text { No evidence of } \\
\text { warmth, Not } \\
\text { listening to/withdrawn } \\
\text { from other }\end{array}$ & $\begin{array}{l}\text { Positive comments/ } \\
\text { reinforcement, } \\
\text { Overt physical affection }\end{array}$ \\
\hline $\begin{array}{l}\text { Task } \\
\text { involvement }\end{array}$ & $\begin{array}{l}\text { Control of the task } \\
\text { through questions } \\
\text { and problem-solving } \\
\text { vs. avoidance }\end{array}$ & $\begin{array}{l}\text { Avoidance of } \\
\text { conversation, } \\
\text { Redirecting the } \\
\text { conversation }\end{array}$ & $\begin{array}{l}\text { Asks most questions, } \\
\text { Concern for task } \\
\text { completion, } \\
\text { Problem-solving }\end{array}$ \\
\hline $\begin{array}{l}\text { Reward } \\
\text { of coping } \\
\text { behaviour }\end{array}$ & $\begin{array}{l}\text { Focus on negatives vs. } \\
\text { positives of situation/ } \\
\text { demonstration of the } \\
\text { belief that child can } \\
\text { cope }\end{array}$ & $\begin{array}{l}\text { Focus on threat/ } \\
\text { dangers, Doubts } \\
\text { child's ability to cope } \\
\text { or succeed }\end{array}$ & $\begin{array}{l}\text { Focus on positives } \\
\text { and/or child's ability to } \\
\text { cope, Modelling coping } \\
\text { strategies }\end{array}$ \\
\hline
\end{tabular}

Ratings were made for each family member every 20 seconds using a scale of 1 (low) to 5 (high). If a family member did not interact sufficiently during the interval to make a meaningful rating, the variables were rated as invalid $(0)$. The overall score for each variable was obtained by averaging the valid ratings for that variable from the two discussions (Note: Preliminary statistical analyses showed that results did not differ when the scores from the two discussions were used independently in the analyses). A registered psychologist who was blind to the children's diagnostic status and the hypotheses of the study completed the coding. The interrater reliability of the coding system was calculated randomly for $30 \%$ of the taped discussions. The second independent coder, also a registered psychologist, was blind to the first coder's ratings, and both coders received training and ongoing supervision in the use of the coding procedure from the authors. All average measure intraclass correlations for absolute agreement between raters ranged between .84 (child's hostility) and .90 (mother's control), with the exception of father's warmth (.74) and father's hostility $(.45)$.

\section{Procedure}

226

Families in the anxious group were referred to the authors by hospitals, medical and psychology clinics, child mental health services and school guidance officers. Free group treatment for anxiety (the FRIENDS program; see Barrett, Lowry-Webster, \& Tumer, $2000 \mathrm{a}, 2000 \mathrm{~b}$ ), comprising 10 weekly sessions and 2 booster sessions, was offered to anxious children and their parents in return for their involvement in the study. Families in the nonclinic group, recruited through school newsletters, were offered a gift voucher to the value of $\$ 30$ in return for their participation. Families were not included in the study if one of the children met DSM-IV diagnostic criteria 
for clinically significant externalising or mood disorders, was taking medication or receiving treatment for their anxiety, or showed evidence of having significant learning disabilities or developmental delays.

Where possible, both parents were interviewed using the DISCAP to determine eligibility for inclusion in the study. Children were interviewed using a short unstructured interview to provide collaborative diagnostic information. In the event of discrepancies between parent and child information, additional questioning was completed using more-structured questions (e.g., relevant subsections of the DISCAP). Two doctoral candidates (clinical psychologists) who were trained and supervised in the administration and scoring of the DISCAP conducted the interviews.

Children completed the RCMAS with a second interviewer who assisted them by reading items, answering questions and helping them to indicate a response when needed. The CBCL-R and the DASS were given to parents to complete at home between assessment sessions.

After obtaining informed consent from all family members, the parent-child interactions were conducted. Each 5-mintue interaction was videotaped for reliability purposes. In a large majority of the interactions, both mothers and fathers participated $(87.8 \%)$.

The procedure for recruitment and assessment for siblings was similar to that described above, with parents also completing the DISCAP and CBCL-R for siblings, and siblings also completing the RCMAS. Parents also completed two discussion tasks with siblings, using the same topics as those used in the interactions with the anxious children. As parents completed two diagnostic interviews and two CBCL-R profiles, the order in which the anxious children and the siblings participated in the discussions was counterbalanced across families.

\section{Design and Analyses}

Section 1. A series of three MANOVAs was performed for the dependent variables control, warmth, task involvement and reward of coping behaviour (parents only). Separate analyses were conducted for mothers, fathers and children. One univariate outlier was identified for reward of coping behaviour for fathers, and thus this case was excluded prior to the analyses. No multivariate outliers were identified (Mahalanobis' distance, $p<.001$ ) and all variables met assumptions for normality, homogeneity of variance, linearity and multicolinearity. To ensure that the experiment-wise Type I error rate remained at .05 , the critical alpha value was prorated to .017 for each of the three separate MANOVAs.

Section 2. Repeated measures MANOVAs were performed using anxious child versus sibling as the within-subjects factor. Separate analyses were conducted for mothers, fathers and children. The dependent variables were control, warmth, task involvement and reward of coping behaviour (parents only). Prior to the analyses, one univariate outlier was removed from each of the father and child analyses. Using Mahalanobis' distance $(p<.001)$, no multivariate outliers were identified. As with Section 1 , the alpha value was reduced to .017 to ensure that the experimentwise rate of Type I errors was confined to a total of $5 \%$.

Section 3. MANOVAs were used to examine the differences between parent-child interactions with siblings of anxious children and parent-child interactions with nonclinic children on the variables control, warmth, task involvement and reward of coping behaviour (parents only). Three analyses were conducted for mothers', fathers' 
TABLE 2

Means and Standard Deviations for the Revised Children's Manifest Anxiety Scale and the Child Behavior Checklist for Anxious Children, Siblings and Nonclinic Control Children

\begin{tabular}{lccccc} 
& RCMAS & \multicolumn{2}{c}{ CBCL-R internalising } & \multicolumn{2}{c}{ CBCL-R externalising } \\
\hline & & Mother & Father & Mother & Father \\
\hline $\begin{array}{l}\text { Anxious child } \\
n=33 \text { (Section 1) }\end{array}$ & $14.72(5.3)^{\mathrm{b}}$ & $66.74(8.5)^{\mathrm{b}}$ & $61.81(7.4)^{\mathrm{b}}$ & $50.34(11.9)$ & $48.52(9.4)$ \\
$\begin{array}{l}\text { Anxious child } \\
n=29 \text { (Section 2) }\end{array}$ & $15(5.4)^{\mathrm{c}}$ & $66(8.7)^{\mathrm{c}}$ & $62.4(7.4)^{\mathrm{c}}$ & $49.54(12.3)$ & $47.83(9.6)$ \\
$\begin{array}{l}\text { Siblings } \\
n=29\end{array}$ & $7.59(6.4)^{\mathrm{c}}$ & $47.7(11.2)^{\mathrm{c}}$ & $42.08(8.4)^{\mathrm{c}, \mathrm{d}}$ & $49.64(11.1)$ & $47.25(10.0)$ \\
$\begin{array}{l}\text { Nonclinic child } \\
n=14\end{array}$ & $7.71(4.5)^{\mathrm{b}}$ & $43.15(6.0)^{\mathrm{b}}$ & $51.22(3.3)^{\mathrm{b}, \mathrm{d}}$ & $46.08(8.6)$ & $49.78(6.5)$ \\
\hline
\end{tabular}

Note: $\mathrm{RCMAS}=$ Revised Children's Manifest Anxiety Scale; $\mathrm{CBCL}-\mathrm{R}=$ Child Behavior Checklist - Revised.

"Sample for Section 2 excludes children whose siblings met criteria for an anxiety disorder bAnxious child vs. nonclinic child; $p<.001$

Target child vs. sibling; $p<.001$

dSibling vs. nonclinic child; $p<.001$

and children's behaviour using an alpha of .017 to indicate significance. Assessment of the assumptions of MANOVA resulted in one univariate outlier being removed for the child analyses.

\section{Results}

\section{Section 1}

Preliminary independent groups $t$ tests were performed using scores on the RCMAS, CBCL-R and DASS to examine between-group differences. The alpha level for significance was set at .01 to control for excessive Type 1 errors. The results confirmed that anxious children were significantly more anxious than the nonclinic children, as indicated by self-report on the RCMAS, $t(44)=4.3, p<.001$, and parent report on the CBCL-R, $t(42)=9.03, p<.001$ (for mothers) and $t(34)=4.11, p<.001$ (for fathers). Shown in Table 2 are the mean scores on the RCMAS and CBCL-R for the various samples used in the three studies. On the RCMAS, anxious children scored an average of $14.72(S D=5.3)$ compared to the $7.71(\mathrm{SD}=4.5)$ scored by nonclinic children.

The average of mothers' internalising scores on the CBCL-R was 66.74 (SD $=$ 8.5) for anxious children and $43.15(\mathrm{SD}=6.0)$ for nonclinic children. The average of fathers' internalising scores was $61.8(S D=7.4)$ for anxious children and 51.22 $(S D=3.3)$ for nonclinic children. No significant differences were found for parental levels of anxiety, depression or stress (DASS) between parents of anxious children and nonclinic control parents.

Using Wilks's criterion for MANOVA, the combined dependent variable of mother's behaviour during the discussion tasks was significantly different between anxious families and nonclinic control families, $F(4,42)=7.955, p<.001, \eta^{2}=.43$, observed power $=.996$. The three variables control, warmth and reward of coping behaviour all significantly contributed to the composite dependent variable; however, due to moderate correlations between these variables, a Roy-Bargmann stepdown 
TABLE 3

Tests of Behaviour During Parent-Child Interactions for Anxious Versus Nonclinic Children

\begin{tabular}{|c|c|c|c|c|c|c|}
\hline \multirow[b]{2}{*}{$\begin{array}{l}\text { Dependent } \\
\text { Variable }\end{array}$} & \multicolumn{3}{|c|}{ Overall MANOVA univariate results } & \multicolumn{3}{|c|}{ Stepdown ANOVA and ANCOVAs } \\
\hline & Univariate $F$ & $d f$ & Obs. power & Stepdown $F$ & $d f$ & Obs. power \\
\hline \multicolumn{7}{|l|}{ Mother } \\
\hline Control & $18.96^{* * *}$ & $1 / 45$ & .989 & $18.96^{* * * *}$ & $1 / 45$ & .989 \\
\hline $\begin{array}{l}\text { Reward of } \\
\text { coping behaviour }\end{array}$ & $12.72 * *$ & $1 / 45$ & .937 & $9.27^{* * *}$ & $1 / 44$ & .845 \\
\hline Warmth & $9.4^{* *}$ & $1 / 45$ & .851 & 0.887 & $1 / 43$ & .151 \\
\hline Task involvement & 3.37 & $1 / 45$ & .435 & & & \\
\hline \multicolumn{7}{|l|}{ Father } \\
\hline Warmth & $11.7 * *$ & $1 / 29$ & .911 & $11.7^{* *}$ & $1 / 29$ & .911 \\
\hline Task involvement & $9.37 * *$ & $1 / 29$ & .841 & 3.99 & $1 / 28$ & .488 \\
\hline Control & $5.31 *$ & $1 / 29$ & .605 & $4.26^{*}$ & $1 / 27$ & .512 \\
\hline $\begin{array}{l}\text { Reward of } \\
\text { coping behaviour }\end{array}$ & 3.07 & $1 / 29$ & .395 & & & \\
\hline \multicolumn{7}{|l|}{ Child } \\
\hline Task involvement & $17.24^{* * *}$ & $1 / 45$ & .982 & $17.24 * * *$ & $1 / 45$ & .982 \\
\hline Warmth & $10.98 * *$ & $1 / 45$ & .900 & 0.425 & $1 / 44$ & .098 \\
\hline Control & 2.04 & $1 / 45$ & .288 & & & \\
\hline
\end{tabular}

Note: ${ }^{*} p<.05, * * p<.01,{ }^{* * *} p<.001$

analysis was used to determine the unique impact of each variable on the composite dependent variable. A stepdown analysis involves assigning priority to each variable based on practical considerations determined by the researcher, and then examining each separate dependent variable in turn. The higher priority dependent variable is tested alone in a univariate ANOVA, while subsequent dependent variables are analysed with the higher priority dependent variable treated as a covariate. In this case, mother's control was the first priority variable, followed in the analysis by mother's reward and mother's warmth.

Shown in Table 3 is that following the stepdown analyses the variables of mother's control, stepdown $F(1,45)=18.96, p<.001, \eta^{2}=.296$, observed power $=$ .989 , and mother's reward of coping behaviour, stepdown $F(1,44)=9.27, p<.01$, $\eta^{2}=.17$, observed power $=.85$, were significantly influenced by the independent variable, whereas warmth did not remain significant after controlling for influence of these other two variables. Mothers of anxious children scored higher on control $(M=3.66)$ and lower on reward of coping behaviour $(M=2.90)$ than mothers of nonclinic children ( $M$ control $=2.60, M$ reward $=3.28$ ).

The overall MANOVA using the father's behaviour variable was also significant, $F(4,26)=5.59, p<.01, \eta^{2}=.46$, observed power $=.95$, with warmth, task involvement and control all found to be significant in the univariate analyses. Following the stepdown analysis (see Table 3), however, only warmth, stepdown $F(1,29)=11.70, p<.01, \eta^{2}=.29$, observed power $=.91$, and control, stepdown $F(1,27)=4.26, p<.05, \eta^{2}=.14$, observed power $=.51$, remained significant. Scores on warmth were lower for fathers of anxious children $(M=2.15)$ than for fathers of nonclinic control children $(M=2.70)$, whereas fathers of anxious children were rated higher on control $(M=3.60)$ than fathers of nonclinic children $(M=2.65)$. 
Likewise, the children's behaviour variable produced a significant overall MANOVA result, $F(3,43)=6.016, p<.01, \eta^{2}=.296$, observed power $=.941$. The variables control and task involvement were significant in the univariate tests; however, only task involvement remained significant following stepdown analyses, stepdown $F(1,45)=17.24, p<.001, \eta^{2}=.28$, observed power $=.982$. Nonclinic children received higher ratings for task completion $(M=3.46)$ than anxious children $(M=2.48)$.

\section{Section 2}

Paired sample $t$ tests showed that the anxious children were significantly more anxious than their siblings, as perceived by themselves (RCMAS scores), $t(27)=7.51$, $p<.001$, and by their parents (CBCL-R scores), $t(26)=8.89, p<.001$ (mothers) and $t(22)=9.42, p<.001$ (fathers). On average, anxious children scored 15 (SD = 5.39 ) on the RCMAS, whereas their siblings scored only $7.59(S D=6.4)$. Motherrated internalising scores on the CBCL-R were $66(S D=8.7)$ for anxious children and $47.7(S D=11.2)$ for their siblings. Similarly, father-rated internalising scores on the CBCL-R were $62.4(\mathrm{SD}=7.4)$ for anxious children and $42.08(\mathrm{SD}=8.4)$ for siblings. Parent-rated externalising behaviour on the CBCL-R did not differ for anxious children and their siblings (see Table 2).

Repeated measures MANOVAs were performed to examine whether the dependent variables control, warmth, task involvement and reward of coping behaviour (parents only) differed between parent-child and parent-sibling interactions. While the results approached significance $(p=.020)$, mother style of interaction was not found to differ between the anxious child and sibling. Similarly, no differences were found between the behaviour of anxious children and their siblings. However, the overall Wilks's Lambda using fathers' behaviours was found to be significant, $F(4,19)=4.92, p<.01, \eta^{2}=.51$, observed power $=.90$, indicating that fathers behaved differently toward their anxious child and their sibling. Post hoc univariate analyses (using a prorated alpha level of .0125) found that fathers' ratings of control differed between children, $F(1,22)=8.07, p<.0125, \eta^{2}=.27$, observed power $=$ .78. Mean observer ratings of fathers' control were $3.57(\mathrm{SD}=.86)$ and $3.36(\mathrm{SD}=$ .77) for anxious child and sibling interactions respectively.

\section{Section 3}

Nonclinic children were rated on the CBCL-R by their fathers as having more internalising problems than were the siblings of anxious children, $t(31)=-4.49$, $p<.001$ (see Table 2). The two groups did not differ on the RCMAS or the CBCL-R externalising scale. Results of the MANOVA indicated that mothers' behaviour with siblings of anxious children differed from that of nonclinic mothers, $F(4,38)=4.066, p<.01, \eta^{2}=.30$, observed power $=.876$; however, comparisons of father and child behaviour were not significant between the two groups. Shown in Table 4 is that while the variables mother's control and warmth were significant in the univariate tests, only mother's control contributed uniquely to the difference between groups, stepdown $F(1,41)=14.478, p<.001, \eta^{2}=.261$, observed power $=.960$. Mothers in the anxious group were rated as being more controlling toward the sibling of their anxious child $(M=3.55)$ than were mothers of nonclinic children $(M=2.60)$. 
TABLE 4

Tests of Behaviour During Parent--Child Interactions for Siblings of Anxious Children Versus Nonclinic Children

\begin{tabular}{lcccccc}
\hline & Overall MANOVA univariate results & \multicolumn{3}{c}{ Stepdown ANOVA and ANCOVAs } \\
\hline $\begin{array}{l}\text { Dependent } \\
\text { Variable }\end{array}$ & Univariate $F$ & $d f$ & Obs. power & Stepdown $F$ & $d f$ & Obs. power \\
\hline Mother & & & & & & \\
Control & $14.48^{* *}$ & $1 / 41$ & .96 & $14.48^{* *}$ & $1 / 41$ & .960 \\
Warmth & $5.07^{*}$ & $1 / 41$ & .594 & 0.213 & $1 / 40$ & .074 \\
$\begin{array}{l}\text { Task involvement } \\
\text { Reward of }\end{array}$ & 3.35 & $1 / 41$ & .431 & & & \\
coping behaviour & 2.18 & $1 / 41$ & .303 & & & \\
\hline
\end{tabular}

Note: ${ }^{*} p<.01,{ }^{* *} p<.001$

\section{Discussion}

The aim of the present research was to examine parent-child interactions with anxious children, and compare them to those with their nonsymptomatic siblings and with nonclinic control children. The results of Section 1 confirmed the findings of previous research, which has found that anxious children experience more control, less warmth and less reward of coping behaviour in their parent-child relationship than do nonclinic children. Hence, Hypothesis 1 was supported.

Hypothesis 2 predicted that parent-child interactions with siblings of anxious children would be similar to the parent-child interactions with the anxious children. This hypothesis was confirmed in Section 2, with the exception of father control. During the discussion tasks, fathers were more controlling of their anxious child than they were of their child's nonanxious sibling. No other significant differences were found for parent or child behaviour during the interactions, suggesting that parents of anxious children exhibit similar behaviours toward both their anxious and nonanxious children. Despite this, however, these results must be considered with caution due to the fact that outcomes were based on a null hypothesis. It is also possible that a host of other factors, such as measurement error, may have contributed to the lack of differences detected.

Finally, the results of Section 3 provided some support for the third hypothesis that parents of anxious children would be more controlling toward their nonanxious children than nonclinic control parents ate with their children. This hypothesis was supported for mother's level of control only. Specifically, mothers in the anxious group were rated as being more controlling of their nonanxious child compared with mothers in the control group. No other parent or child behavioural variables were found to differ significantly between the two samples. Obviously further research is required to address this area, perhaps with a large sample size to improve power and with the use of numerous measures of parent-child interactions, including observational and self-report.

The results of Section 1 provided additional support for the link between parental behaviour and childhood anxiety. Further, mothers' level of control was consistently high with both their anxious and nonsymptomatic children in comparison to the levels displayed by mothers of nonclinic children. This may indicate that high control may be characteristic of mothers of anxious children, which may 
interact with the behaviour of the child to produce anxiety. Alternatively, the process of rearing an anxious child may result in the need to be more directive and controlling and this style is then generalised to both anxious and nonanxious children. In contrast, fathers of anxious children exhibited high levels of control only with their anxious child. Thus, this finding that paternal control is specific to the anxious child gives weight to the possibility that the child's anxiety has played a role in the resulting style of father-child interaction.

Taken together, the results of the current study demonstrate that high control and, to a lesser degree, low levels of warmth may be salient features in parent interactions with their anxious children and with their anxious children's siblings. The process by which this pattern of parent-child and parent-sibling interaction occurs is of theoretical interest. One possibility is that anxious behaviour in a child creates an environment whereby parents become more controlling in an attempt to deal with the problem. Over time, this parenting style may not remain specific to the anxious child and may become a feature of all parent-child interactions within the family. Another possibility is that a controlling parenting style may be characteristic of one or both of the parents, and thus it is used for all children in the family. However, when this parenting style is combined with, and possibly enhanced by, a predisposition in a vulnerable child, it resultantly leads to that child developing an anxiety disorder.

\section{Limitations}

Despite the promising results of the study, the cross-sectional design of the present research does not permit speculation on the direction of causality for the associations between parent-child interaction style and childhood anxiety. Longitudinal designs are therefore important for future researchers to consider undertaking. Measures of family interaction across time would better allow researchers to answer questions on the process by which these parent-child interaction styles develop.

Caution is required in interpreting the analyses of father behaviour due to the small number of valid cases. Despite a high rate of father involvement for the twoparent families, the number of single mother families resulted in only a small group of fathers participating in the interactions. While the analyses of father behaviour are far from conclusive, it is noteworthy that there is a high degree of consistency between the findings for mother and father behaviour.

Another limitation of the present research affecting studies 1 and 3 is the small nonclinic sample size and the resulting unequal cell sizes that are not desirable in MANOVA analyses. While this issue indicates a need for caution in interpreting the findings of these two studies, it was noted that the unequal cell sizes did not result in the assumption of homogeniety of variance being violated for any of the analyses. In addition, the analyses for studies 1 and 3 were recalculated after randomly deleting cases to create equal cell sizes, and the pattern of these results was so similar to that of the full data set that the original complete analyses were retained. Finally, supporting the validity of the results is that they are consistent with previous findings.

As a final point, the age range of children included in this study was large. Perhaps age played a part in the results found here.

\section{Future Research}

Despite these limitations, this present research represents an advancement in the study of anxious children and their parents by including their nonsymptomatic 
siblings as a comparison group. Thus, the information provided by the current findings is important in the unique insight it provides into the family system beyond the anxious child alone. It is hoped that this study will promote further research using this approach.

Replication of the current results is important, particularly with larger samples of fathers. With the marked increase in research attention on the role of parenting in childhood anxiety, the question of whether this behaviour is exclusive to the anxious child or common to all children in the family is pertinent. To address this question, further research is needed in which a broader range of parenting behaviours and different assessment techniques are used, including self-report, interview and observation in a variety of settings. In addition, longitudinal research aimed at assessing child and sibling temperamental predisposition to anxiety would better inform on the proposed interactional model between child and parenting behaviour.

The family system is complex and any attempts to understand it may require novel and innovative approaches to examine the various aspects. The use of siblings as a comparison group for anxious children is only one such way to do this. As one of the first studies to examine parent interactions with nonsymptomatic siblings of disordered children, it is hoped that the present research prompts further investigation.

\section{References}

Achenbach, T.M. (1991). Manual for the Child Behaviour Checklist/ 4-18 and 1991 profile. Burlington, VT: University of Vermont, Department of Psychiatry.

Achenbach, T.M., \& Edelbrock, C.S. (1983). Manual for the Child Behaviout Checklist and Revised Child Behaviour Profile. Burlington, VT: University of Vermont.

American Psychiatric Association. (1994). Diagnostic and statistical manual of mental disorders (4th ed.). Washington, DC: Author.

Barrett, P.M., Rapee, R.M., Dadds, M.R., \& Ryan, S.M. (1996). Family enhancement of cognitive style in anxious and aggressive children. Joumal of Abnomal Child Psychology, 24, 187-203.

Barrett, P., Lowry-Webster, H., \& Turner, C. (2000a). FRIENDS for children: Group leader's manual. Brisbane, Australia: Australian Academic Press.

Barrett, P., Lowry-Webster, H., \& Tumer, C. (2000b). FRIENDS for children: Workbook. Brisbane, Australia: Australian Academic Press.

Brown, T.A., Chorpita, B.F, Korotitsch, W., \& Barlow, D.H. (1997). Psychometric properties of the Depression Anxiety Stress Scales (DASS) in clinical samples. Behaviour Research and Therapy, 35, 79-89.

Chorpita, B.F, Albano, A.M., \& Barlow, D.H. (1996). Cognitive processing in children: Relationship to anxiety and family influences. Journal of Clinical Child Psychology, 25, 170-176.

Chorpita, B.F, Brown, T.A., \& Barlow, D.H. (1998). Perceived control as a mediator of family environment in etiological models of childhood anxiety. Behavior Therapy, 29, 457-476.

Clara, I.P., Cox, B.J., \& Enns, M.W. (2001). Confirmatory factor analysis of the DepressionAnxiety-Stress Scales in depressed and anxious patients. Journal of Psychopathology and Behavioral Assessment, 23, 61-67.

Cobham, V.E. (1998). The case for involving the family in the treatment of childhood anxiety. Behaviour Change, 15, 203-212.

Cobham, V.E., Dadds, M.R., \& Spence, S.H. (1999). Anxious children and their parents: What do they expect. Joumal of Clinical Child Psychology, 28, 220-231.

Dadds, M.R., \& Barrett, P.M. (1996). Family processes in child and adolescent anxiety and depression. Behaviour Change, 13, 231-239.

Daniels, D. (1986). Differential experiences of siblings in the same family as predictors of adolescent sibling personality differences. Joumal of Personality and Social Psychology, 51, 339-346. 
Dumas, J.E., \& LaFreniere, PJ. (1993) Mother-child relationships as sources of support of stress: A comparison of competent, average, aggressive and anxious dyads. Child Development, 64 , $1732-1754$.

Dumas, J.E., LaFreniere, P.j., \& Serketich, W.J. (1995). "Balance of Power": A transactional analysis of control in mother-child dyads involving socially competent, aggressive, and anxious children. Joumal of Abnormal Psychology, 104, 104-113.

Dunn, J., \& Plomin, R. (1991). Why are siblings so different? The significance of differences in sibling experiences within the family. Family Process, 30, 271-283.

Dunn, ]., Stocker, C., \& Plomin, R. (1990). Nonshared experiences within the family: Correlates of behaviour problems in middle childhood. Development and Psychopathology, 2, 113-126.

Fox, T.L., Barrett, P.M., \& Shortt, A.L. (2002). Sibling relationships of anxious children. Joumal of Clinical Child and Adolescent Psychology, 31, 375-383.

Ginsburg, G.S., Silverman, W.K., \& Kurtines, W.K. (1995). Family involvement in treating children with phobic and anxiety disorders: A look ahead. Clinical Psychology Review, 15, 457-475.

Grüner, K., Muris, P., \& Merckelbach, H. (1999). The relationship between anxious rearing behaviours and anxiety disorders symptomatology in normal children. Journal of Behavior Therapy and Experimental Psychiatry, 30, 27-35.

Hoffman, L.W. (1991). The influence of the family environment on personality: Accounting for sibling differences. Psychological Bulletin, 110, 187-203.

Holland, D., \& Dadds, M. (1995). Diagnostic Interview Schedule for Child, Adolescents and Parents. Brisbane, Australia: Griffith University.

Hudson, J.L., \& Rapee, R.M. (2002). Parent-child interactions in clinically anxious children and their siblings. Journal of Clinical Child and Adolescent Psychology, 31(4), 548-555.

Johnson, S., Bartett, P.M., Dadds, M.R., Fox, T.L., \& Shorte, A.L. (1999). The Diagnostic Interview Schedule for Children, Adolescents, and Parents: Initial reliability and validity data. Behaviour Change, 16, 155-164.

Krohne, H.W., \& Hock, M. (1993). Coping dispositions, actual anxiety, and the incidental learning of success and failure-related stimuli. Personality and Individual Differences, 15, 33-41.

Last, C.G., \& Strauss, C.C. (1990). School refusal in anxiety-disordered children and adolescents. Journal of the American Academy of Child and Adolescent Psychiatry, 29, 31-35.

Lovibond, P.E, \& Lovibond, S.H. (1995). The structure of negative emotional states: Comparison of the Depression Anxiety Stress Scales (DASS) with the Beck depression and anxiety inventories. Behaviour Research and Therapy, 33, 335-343.

Lovibond, S.H., \& Lovibond, P.F (1993). Manual for the Depression Anxiety Stress Scales (DASS) (Psychology Foundation Monograph). Sydney, Australia: University of New South Wales.

Manassis, K. (2001). Child-parent relations: Attachment and anxiety disorders. In W.K. Silverman \& P.D.A. Treffers (Eds.), Anxiety disorders in children and adolescents: Research, assessment and intervention (pp. 255-272). Cambridge, UK: Cambridge University Press.

Messer, S.C., \& Beidel, D.C. (1994). Psychosocial correlates of childhood anxiety disorders. Joumal of the American Academy of Child and Adolescent Psychiatry, 33, 975-983.

Minuchin, S. (1974). Families \& family therapy. Oxford, England: Harvard University Press.

Muris, P., \& Merckelbach, H. (1998). Perceived parental rearing behaviour and anxiety disorders symptoms in normal children. Personality and Individual Differences, 25, 1199-1206.

O'Connor, T.G., Hetherington, E.M., Reiss, D., \& Plomin, R. (1995). A twin-sibling study of observed parent-adolescent interactions. Child Development, 66, 812-829.

Perrin, S., \& Last. C.G. (1992). Do childhood anxiety measures measure anxiety? Journal of Abnormal Child Psychology, 20, 567-578.

Plomin, R., \& Daniels, D. (1987). Why are children in the same family so different from one another? Behavioral and Brain Sciences, 10, 1-60.

Rapee, R.M. (1997). Potential role of childrearing practices in the development of anxiety and depression. Clinical Psychology Review, 17, 47-68. 
Rende, R.D., Slomkowski, C.L., Stocker, C., Fulker, D.W., \& Plomin R. (1992). Genetic and environmental influences on maternal and sibling interaction in middle childhood: A sibling adoption study. Developmental Psychology, 28, 484-490.

Reynolds, C.R., \& Richmond, B.O. (1978). A revised measure of the Children's Manifest Anxiety Scale. Joumal of Abnormal Child Psychology, 6, 271-280.

Reynolds, C.R., \& Richmond, B.O. (1985). Revised Children's Manifest Anxiety Scale. Los Angeles: Western Psychological Service.

Rowe, D.C., \& Plomin, R. (1981). The importance of nonshared (E-sub-1) environmental influence in behavioral development. Developmental Psychology, 17, 517-530.

Shortt, A.L., Barrett, P.M., Dadds, M.R., \& Fox, T.L. (2001). The influence of family and experimental context on cognition in anxious childzen. Joumal of Abnomal Child Psychology, 29, $585-596$.

Silverman, W.K., Cerny, J.A., Nelles, W.B, \& Burke, A.E. (1988). Behaviour problems in children of parents with anxiety disorders. Journal of the American Academy of Child and Adolescent Psychiatry, 27, 779-784.

Siqueland, L., Kendall, P.C., \& Steinberg, L. (1996). Anxiety in children: Perceived family environments and observed family interaction. Joumal of Clinical Child Psychology, 25, 225-237.

Stark, K.D., Humphrey, L.L., Crook, K., \& Lewis, K. (1990). Perceived family environments of depressed and anxious children: Child's and maternal figure's perspectives. Joumal of Abnormal Child Psychology, 18, 527-547. 